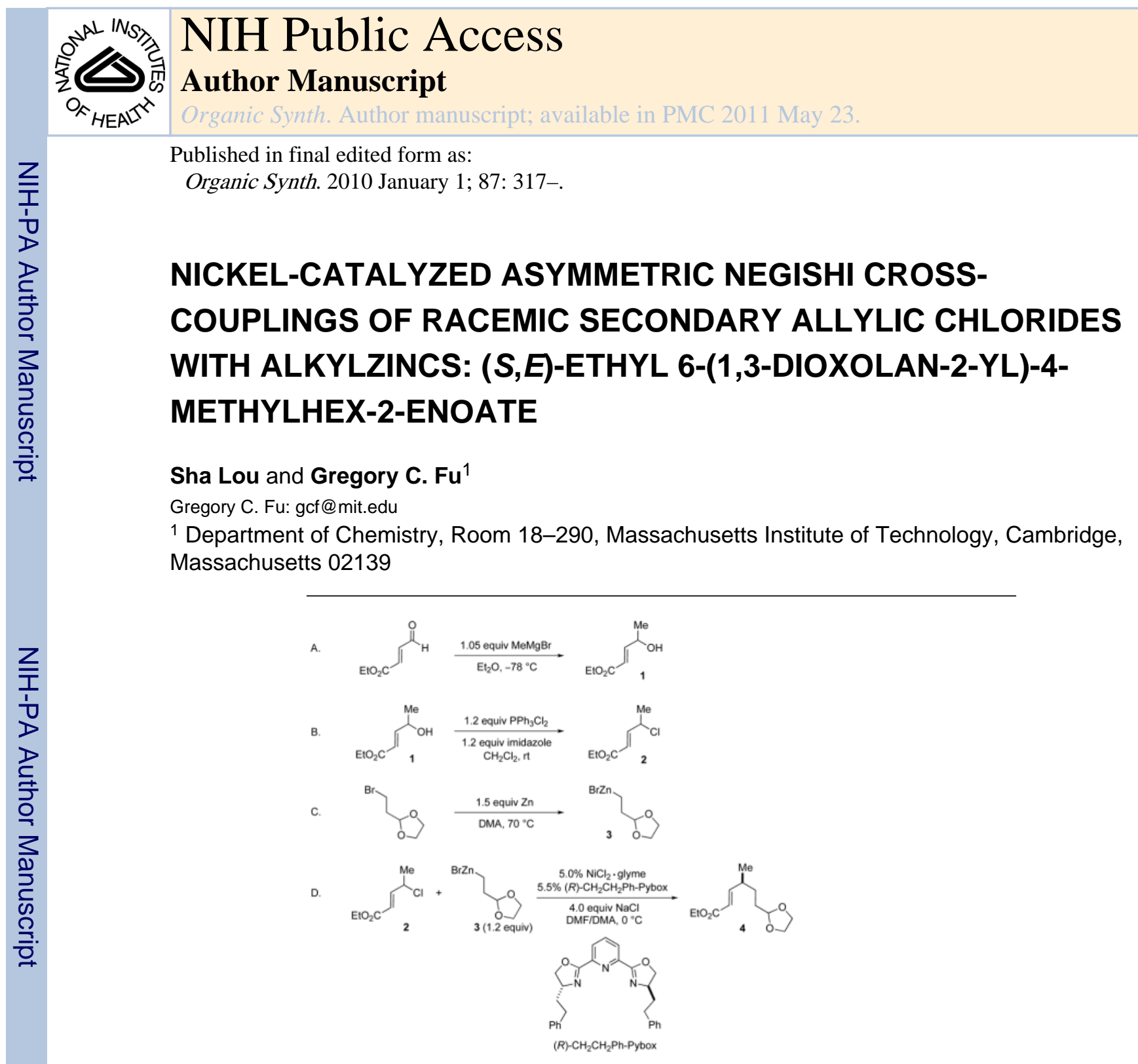

\title{
1. Procedure
}

\section{A. Ethyl (E)-4-hydroxy-2-pentenoate (1)}

An oven-dried, 1000-mL, two-necked, round-bottomed flask equipped with a rubber septum, an argon inlet, and a magnetic stirbar was purged with argon and charged with $\mathrm{Et}_{2} \mathrm{O}$ $(500 \mathrm{~mL})$ (Note 1) and ethyl (E)-4-oxo-2-butenoate ( $24.1 \mathrm{~mL}, 25.6 \mathrm{~g}, 200 \mathrm{mmol}, 1.0$ equiv) (Note 2). The solution was cooled to $-78^{\circ} \mathrm{C}$ in a dry ice/acetone bath, and then $\mathrm{MeMgBr}$ (3.0 $\mathrm{M}$ in $\mathrm{Et}_{2} \mathrm{O} ; 70.0 \mathrm{~mL}, 210 \mathrm{mmol}, 1.05$ equiv) (Note 3) was added dropwise via syringe pump $(2.0 \mathrm{~mL} / \mathrm{min}$ ) over $35 \mathrm{~min}$ (The slow addition can also be conducted via a $100-\mathrm{mL}$ pressure-equalizing addition funnel fitted with a septum). After the addition was complete, the reaction mixture was stirred for an additional $2 \mathrm{~h}$ at $-78^{\circ} \mathrm{C}$. During the course of the reaction, the precipitation of white solids led to a heterogeneous reaction mixture. The progress of the reaction can be followed by TLC analysis on silica gel $\left(20 \% \mathrm{Et}_{2} \mathrm{O} /\right.$ hexanes as the eluent; visualization with a UV lamp or with a $\mathrm{KMnO}_{4}$ stain; the aldehyde starting

\footnotetext{
${ }^{1} \mathrm{Et}_{2} \mathrm{O}(99+\%)$ was purchased from J.T. Baker (water content: $<10 \mathrm{ppm}$ ) and purified by passage through activated alumina under argon.

${ }_{2}^{2}$ Ethyl (E)-4-oxo-2-butenoate (96\%) was purchased from Alfa Aesar and used as received.

${ }^{3} \mathrm{MeMgBr}\left(3.0 \mathrm{M}\right.$ in $\left.\mathrm{Et}_{2} \mathrm{O}\right)$ was purchased from Aldrich and used as received.
} 
material has $\mathrm{R}_{f}=0.8$, and the alcohol product has $\mathrm{R}_{f}=0.3$ ) (Note 4). Then, the dry ice/ acetone bath was removed, and the reaction mixture was carefully poured over 5 min into a rapidly stirred, $0{ }^{\circ} \mathrm{C}$ saturated aqueous solution of $\mathrm{NH}_{4} \mathrm{Cl}(300 \mathrm{~mL})$ in a 2-L Erlenmeyer flask equipped with a magnetic stirbar. The two-necked flask was washed with a saturated aqueous solution of $\mathrm{NH}_{4} \mathrm{Cl}(100 \mathrm{~mL})$ and then $\mathrm{Et}_{2} \mathrm{O}(100 \mathrm{~mL})$. The aqueous solution and the organic solution were combined and transferred to a 2-L separatory funnel. The aqueous phase was separated and extracted with $\mathrm{Et}_{2} \mathrm{O}(200 \mathrm{~mL} \times 3)$. The organic layers were combined, dried over $\mathrm{MgSO}_{4}(30 \mathrm{~g})$, and filtered through a Büchner funnel that contained a bed of celite (1.0 cm height). The filtrate was concentrated by rotary evaporation (20 torr). The residue was loaded onto a wet-packed (hexanes) column of silica gel $(8 \mathrm{~cm}$ diameter $\times$ $22 \mathrm{~cm}$ height; $250 \mathrm{~g}$ ) and eluted with a gradient of $\mathrm{Et}_{2} \mathrm{O}$ in hexanes $(500 \mathrm{~mL}$ of hexanes; 1.0 $\mathrm{L}$ of $15 \% \mathrm{Et}_{2} \mathrm{O} /$ hexanes, $1.0 \mathrm{~L}$ of $20 \% \mathrm{Et}_{2} \mathrm{O}$ in hexanes, $1.0 \mathrm{~L}$ of $30 \% \mathrm{Et}_{2} \mathrm{O} / \mathrm{hexanes}, 1.0 \mathrm{~L}$ of 50\% $\mathrm{Et}_{2} \mathrm{O} /$ hexanes; fraction size: $100 \mathrm{~mL}$ ) (Note 5) (TLC analysis on silica gel: $30 \%$ $\mathrm{Et}_{2} \mathrm{O} /$ hexanes as eluent, visualization with a UV lamp and a $\mathrm{KMnO}_{4}$ stain, $\mathrm{R}_{f}=0.5$ ) (Note 4). The desired allylic alcohol 1 (21.7-23.4 g, 75-81\% yield) was obtained as a yellow oil (Note 6).

\section{B. Ethyl (E)-4-chloropent-2-enoate (2)}

An oven-dried, 500-mL, two-necked, round-bottomed flask equipped with a rubber septum, an argon inlet, and a magnetic stirbar was purged with argon and charged with $\mathrm{CH}_{2} \mathrm{Cl}_{2}$ via syringe (200 mL) (Note 7) and ethyl (E)-4-hydroxy-2-pentenoate (1) $(14.4 \mathrm{~g}, 100 \mathrm{mmol}$, 1.00 equiv). The solution was cooled to $0{ }^{\circ} \mathrm{C}$ in an ice bath, and dichlorotriphenylphosphorane ( $40.0 \mathrm{~g}, 120 \mathrm{mmol}, 1.20$ equiv) (Note 8) was added, followed by imidazole ( $8.17 \mathrm{~g}, 120 \mathrm{mmol}, 1.20$ equiv) (Note 9). The solution was allowed to warm to $\mathrm{rt}$, and then it was stirred for $6 \mathrm{~h}$, during which time a white precipitate formed. The progress of the reaction can be followed by TLC analysis on silica gel $\left(20 \% \mathrm{Et}_{2} \mathrm{O} /\right.$ hexanes as the eluent; visualization with a UV lamp or with a $\mathrm{KMnO}_{4}$ stain; the alcohol starting material has $\mathrm{R}_{f}=0.3$, and the chloride product has $\mathrm{R}_{f}=0.8$ ) (Note 4$)$. Pentane $(150 \mathrm{~mL})$ and ether $(150 \mathrm{~mL})$ were added, and the white precipitate was removed by filtration through silica gel ( $8 \mathrm{~cm}$ diameter $\times 10 \mathrm{~cm}$ height). The silica was washed with pentane/ether $(1 / 1 ; 200 \mathrm{~mL})$. The combined organic layers were concentrated by rotary evaporation (20 torr), and the residue was transferred to a 50-mL round-bottomed flask equipped with a magnetic stirbar. The product was distilled under reduced pressure $\left(30\right.$ torr, $\left.85-90^{\circ} \mathrm{C}\right)$ though a short-path distillation head to afford the desired allylic chloride (2) (12.6-13.4 g, 78-83\% yield) as a colorless oil (Note 10).

\footnotetext{
${ }_{5}^{4}$ Analytical thin-layer chromatography was performed using EMD $0.25 \mathrm{~mm}$ silica gel $60-\mathrm{F}$ plates.

${ }^{5}$ Column chromatography was performed on Sorbent Technologies $60 \AA$ silica gel.

${ }^{6}$ Compound 1 has the following properties: ${ }^{1} \mathrm{H}$ NMR $\left(\mathrm{CDCl}_{3}, 500 \mathrm{MHz}\right) \delta: 6.93(\mathrm{dd}, J=16.0,6.0 \mathrm{~Hz}, 1 \mathrm{H}), 5.99(\mathrm{~d}, J=16.0 \mathrm{~Hz}, 1 \mathrm{H})$, 4.46-4.49 (m, 1H), $4.18(\mathrm{q}, J=7.0 \mathrm{~Hz}, 2 \mathrm{H}), 1.63(\mathrm{br} \mathrm{s}, 1 \mathrm{H}), 1.32(\mathrm{~d}, J=7.0 \mathrm{~Hz}, 3 \mathrm{H}), 1.27(\mathrm{t}, J=7.0 \mathrm{~Hz}, 3 \mathrm{H}) .{ }^{13} \mathrm{C} \mathrm{NMR}\left(\mathrm{CDCl}_{3}, 100\right.$ MHz) $\delta$ : $167.0,151.5,119.4,67.0,60.6,22.6,14.3$. The spectral data are in agreement with reported values. 2 The purity $(>98 \%)$ was determined by GC analysis $\left(\mathrm{t}_{\mathrm{r}}=2.71 \mathrm{~min}\right.$; HP 6890 Series GC system equipped with a DB-1 column (length $30 \mathrm{~m}$, I.D. $0.25 \mathrm{~mm}$, film $0.25 \mu \mathrm{m})$; carrier gas: $\mathrm{H}_{2}(45 \mathrm{~mL} / \mathrm{min})$; gradient temperature: hold at $100^{\circ} \mathrm{C}$ for $1 \mathrm{~min}, 100 \rightarrow 280{ }^{\circ} \mathrm{C}$ at $40{ }^{\circ} \mathrm{C} / \mathrm{min}$, hold at $280{ }^{\circ} \mathrm{C}$ for $2 \mathrm{~min}$ )

${ }^{7}$ Dichloromethane (>99.8\%) was purchased from J.T. Baker (water content: $<0.02 \%$ ) and purified by passage through activated alumina under argon.

${ }_{9}^{8}$ Dichlorotriphenylphosphorane $(95 \%)$ was purchased from Aldrich and used as received.

${ }^{9}$ Imidazole (99\%) was purchased from Alfa Aesar and used as received.

${ }^{10}$ Compound 2 has the following properties: ${ }^{1} \mathrm{H}$ NMR $\left(\mathrm{CDCl}_{3}, 500 \mathrm{MHz}\right) \delta: 6.95(\mathrm{dd}, J=15.5,7.0 \mathrm{~Hz}, 1 \mathrm{H}), 6.03(\mathrm{dd}, J=15.5,1.5$ $\mathrm{Hz}, 1 \mathrm{H}), 4.63$ (doublet of pentets, $J=7.0,1.5 \mathrm{~Hz}, 1 \mathrm{H}), 4.23(\mathrm{q}, J=7.5 \mathrm{~Hz}, 2 \mathrm{H}), 1.66(\mathrm{~d}, J=7.0 \mathrm{~Hz}, 3 \mathrm{H}), 1.32(\mathrm{t}, J=7.0 \mathrm{~Hz}, 3 \mathrm{H}) ;{ }^{13} \mathrm{C}$ NMR (CDCl $3,100 \mathrm{MHz}) \delta: 166.1,147.2,121.9,60.9,55.0,24.4,14.4$; IR (film) 2983, 1722, 1660, 1446, 1368, 1271, 1181, 1034, $975 \mathrm{~cm}^{-1}$; GCMS calcd for $\mathrm{C}_{7} \mathrm{H}_{11} \mathrm{ClO}_{2}$ (M) 162 , found 162 . The purity $(>98 \%)$ was determined by $\mathrm{GC}$ analysis $\left(\mathrm{t}_{\mathrm{r}}=2.65 \mathrm{~min}\right)$, using the same conditions as for compound $\mathbf{1}$.
} 


\section{2-[2-(1,3-Dioxolan-2-yl)ethyl]zinc bromide (3)}

An oven-dried, 200-mL, pear-shaped Schlenk flask equipped with a rubber septum and a magnetic stirbar was purged with argon for $5 \mathrm{~min}$ and charged with zinc powder $(9.80 \mathrm{~g}$, $150 \mathrm{mmol}, 1.50$ equiv) (Note 11$)$. The zinc was heated under vacuum $\left(0.5\right.$ torr) at $70{ }^{\circ} \mathrm{C}$ in an oil bath for $30 \mathrm{~min}$. Anhydrous $\mathrm{N}, \mathrm{N}$-dimethylacetamide (DMA; $100 \mathrm{~mL}$ ) (Note 12 ) and $\mathrm{I}_{2}$ (634 $\mathrm{mg}, 2.50 \mathrm{mmol}, 0.0250$ equiv) (Note 13) were added. The red-gray solution was stirred at $70{ }^{\circ} \mathrm{C}$ until the red color faded ( 5 min). 2-(1,3-Dioxolan-2-yl)ethyl bromide (12.0 mL, $100 \mathrm{mmol}, 1.00$ equiv) (Note 14) was added via syringe over $3 \mathrm{~min}$, and then the reaction mixture was stirred at $70{ }^{\circ} \mathrm{C}$ for $12 \mathrm{~h}$. Next, the mixture was allowed to cool to rt, and the unreacted zinc powder was removed by filtration under argon (see Figure 1). The clear yellow solution was employed in the next step without further purification. No-D ${ }^{1} \mathrm{H}$ NMR spectroscopy was used to determine that the concentration of the alkylzinc solution was 0.80 M (Note 15).

\section{D. (S,E)-Ethyl 6-(1,3-dioxolan-2-yl)-4-methylhex-2-enoate (4)}

An oven-dried, 1000-mL, three-necked, round-bottomed flask equipped with a thermometer inlet and thermometer, an argon inlet, a rubber septum, and a magnetic stirbar was purged with argon for $20 \mathrm{~min}$. Under a positive pressure of argon, anhydrous $\mathrm{NaCl}(10.4 \mathrm{~g}, 177$ mmol, 4.00 equiv) (finely ground and dried at $120^{\circ} \mathrm{C}$ under vacuum overnight) (Note 16 and Note 17) was added, followed by $\mathrm{NiCl}_{2} \cdot$ glyme ( $485 \mathrm{mg}, 2.22 \mathrm{mmol}, 0.0500$ equiv) (Note 18) and (R)- $\mathrm{CH}_{2} \mathrm{CH}_{2} \mathrm{Ph}$-Pybox (1.04 g, $2.44 \mathrm{mmol}, 0.0550$ equiv) (Note 19 and Note 20). Anhydrous DMF (222 mL) (Note 21) and anhydrous DMA (155 mL) (Note 22) were then added via syringe, and the flask was capped with a rubber septum. This solution of the catalyst was stirred at $0{ }^{\circ} \mathrm{C}$ for $20 \mathrm{~min}$ in an isopropanol bath cooled by a chiller system (Note 23). Ethyl (E)-4-chloropent-2-enoate (2) $(7.20 \mathrm{~g}, 44.3 \mathrm{mmol}, 1.00$ equiv) was added, and then 2-[2-(1,3-dioxolan-2-yl)ethyl]zinc bromide (3) (66 mL, 0.80 M in DMA, $53 \mathrm{mmol}$, 1.2 equiv) was added via syringe over $10 \mathrm{~min}$. Throughout the addition of the alkylzinc reagent, the temperature of the solution was maintained at $0{ }^{\circ} \mathrm{C}$. The reaction mixture was

\footnotetext{
$11_{\text {Zinc powder }}(99.9 \%, \sim 100$ mesh) was purchased from Alfa Aesar and used as received.

12 Anhydrous DMA ( $\geq 99.5 \%$, over molecular sieves) purchased from Fluka (water content: 6.9 ppm, determined with a 831 Karl Fisher Coulometer) or anhydrous DMA (99.8\%) purchased from Aldrich (water content: $14 \mathrm{ppm}$ ) were used as received.

${ }^{13} \mathrm{I}_{2}(\geq 99 \%$, chips) was purchased from Aldrich and used as received.

142 -(1,3-Dioxolan-2-yl)ethyl bromide (95\%) was purchased from Alfa Aesar and used as received.

${ }^{15}$ For the No-D NMR ( $\mathrm{pw}=1.5$ ) experiment, a ${ }^{1} \mathrm{H}$ NMR spectrum of a blank $\mathrm{CDCl}_{3}$ sample was taken to lock the sample and determine the reference. Then, an unlocked No-D NMR spectrum of the alkylzinc sample in DMA was taken $(\mathrm{pw}=1.5)$. The resonances for DMA appear at $\delta 3.44,3.25$, and 2.32. The resonance for the $\mathrm{CH}_{2} \mathrm{Zn}$ protons of $\mathrm{RZnBr}$ appears at $\delta 0.32$. The resonance for the terminal Me group of the reduction product appears at $\delta 1.15$. The molar ratio of DMA: RZnBr: RH (X: $1: \mathrm{Y})$ was determined by No-D NMR to be 10.5: 1: 0.13 . The density (d) of the solution was measured to be $0.940 \mathrm{~g} / \mathrm{mL}$. The final concentration of alkylzinc was calculated to be $0.80 \mathrm{M}$ according to the equation:

$[\mathrm{RZnBr}]=\mathrm{d} \times 1000 /\left(\mathrm{X} \times \mathrm{MW}_{\mathrm{DMA}}+\mathrm{MW}_{\mathrm{RZnBr}}+\mathrm{Y} \times \mathrm{MW}_{\mathrm{RH}}\right)$.

${ }^{16} \mathrm{NaCl}(99.5 \%)$ was purchased from Mallinckrodt Chemicals and ground to a fine powder and dried under vacuum at $120^{\circ} \mathrm{C}$ overnight before use. The use of anhydrous $\mathrm{NaCl}$ beads ( $99.99 \%$ from Aldrich) or $\mathrm{NaCl}$ ( $99.5 \%$ from Mallinckrodt Chemicals) powder that was oven-dried in the air furnished lower yields (30\% and $74 \%$, respectively).

${ }^{17}$ The presence of $\mathrm{NaCl}$ has a substantial impact on the rate of the cross-coupling, but little impact on the ee. The role of the $\mathrm{NaCl}$ may be to increase the ionic strength of the reaction mixture (the use of more polar solvents is generally advantageous) or to activate the organozinc reagent. 3

${ }^{18} \mathrm{NiCl}_{2} \cdot$ glyme was purchased from Strem and used as received.

$19(R)$ - or $(S)-\mathrm{CH}_{2} \mathrm{CH}_{2} \mathrm{Ph}$-Pybox can be prepared via the reaction of 2-amino-4-phenylbutan-1-ol with 2,6-pyridinedicarbonitrile catalyzed by $5 \%$ zinc triflate in toluene at reflux. 4

$20(S)-\mathrm{CH}_{2} \mathrm{CH}_{2} \mathrm{Ph}$-Pybox $(97 \%)$ may be purchased from Aldrich and used as received.

21 Anhydrous DMF ( $\geq 99.5 \%$, over molecular sieves) was purchased from Aldrich (water content: $<0.005 \%$ ) and used as received.

${ }^{22}$ When anhydrous DMA ( $\geq 99.5 \%$, over molecular sieves) purchased from Fluka (water content: 6.9 ppm, determined with a 831 Karl Fisher Coulometer) or anhydrous DMA (99.8\%) purchased from Aldrich (water content: 14 ppm) was used as received, the cross-coupling product was obtained in good yield (>90\%). However, the use of DMA with a higher water content (e.g, $77 \mathrm{ppm})$ led to a lower yield of product $(\sim 75 \%)$.

${ }^{23}$ When the reaction was conducted at $-10{ }^{\circ} \mathrm{C}$ on a 10 -g scale, the cross-coupling proceeded more slowly, resulting in a $52 \%$ yield after $24 \mathrm{~h}$.
} 
stirred for $24 \mathrm{~h}$ at $0{ }^{\circ} \mathrm{C}$. The progress of the reaction can be followed by GC analysis (Note 24). After the reaction was complete, water $(400 \mathrm{~mL})$ was added over 20 min to quench the excess organozinc reagent, during which time the temperature of the reaction mixture was kept below $25^{\circ} \mathrm{C}$. After the addition of water was complete, the solution was stirred at $\mathrm{rt}$ for an additional $10 \mathrm{~min}$, and then it was extracted with $\mathrm{Et}_{2} \mathrm{O}(200 \mathrm{~mL} \times 3)$. The combined organic layers were washed with water $(200 \mathrm{~mL} \times 2)$, dried over anhydrous $\mathrm{Na}_{2} \mathrm{SO}_{4}(30 \mathrm{~g})$, filtered through a Büchner funnel that contained a bed of celite $(1.0 \mathrm{~cm}$ height), and concentrated by rotary evaporation ( 20 torr). The residue was loaded onto a wet-packed (hexanes) column of silica gel $(7 \mathrm{~cm}$ diameter $\times 30 \mathrm{~cm}$ height; $350 \mathrm{~g}$ ) and eluted with a gradient of $\mathrm{Et}_{2} \mathrm{O}$ in hexanes $\left(500 \mathrm{~mL}\right.$ of hexanes, $2.0 \mathrm{~L}$ of $5 \% \mathrm{Et}_{2} \mathrm{O} /$ hexanes, $2.0 \mathrm{~L}$ of $10 \%$ $\mathrm{Et}_{2} \mathrm{O} /$ hexanes, $2.0 \mathrm{~L}$ of $15 \% \mathrm{Et}_{2} \mathrm{O} /$ hexanes) (Note 5) (TLC analysis on silica gel: $10 \% \mathrm{Et}_{2} \mathrm{O} /$ hexanes as eluent, visualization with a $\mathrm{KMnO}_{4}$ stain, $\mathrm{R}_{f}=0.5$ ) (Note 4$)$. The desired crosscoupling product $4(9.50-9.71 \mathrm{~g}, 94-96 \%$ yield, $94-95 \%$ ee) was obtained as a colorless oil (Note 24).

\section{Waste Disposal Information}

All toxic materials were disposed of in accordance with "Prudent Practices in the Laboratory"; National Academy Press; Washington, DC, 1995.

\section{Discussion}

The transition metal-catalyzed enantioselective coupling of allylic electrophiles with carbon nucleophiles has been the focus of intense investigation.5 Salient examples include palladium-catalyzed couplings with enolates, nickel-catalyzed couplings with Grignard reagents, and copper-catalyzed couplings with Grignard and diorganozinc reagents. 6 Despite impressive progress, the development of methods that have broader scope with respect to the nucleophile, as well as improved functional-group compatibility, persist as important challenges.

This work describes a nickel-based catalyst for the asymmetric cross-coupling of racemic secondary allylic chlorides with readily available alkylzinc halides (Eq 1). 7, 8, 9 The process is stereoconvergent: both enantiomers of the substrate are transformed into the same enantiomer of the product with high stereoselectivity.

\footnotetext{
${ }^{24}$ The product was generated with $>20: 1 \mathrm{E}: \mathrm{Z}$ selectivity and $>20: 1$ regioselectivity. Compound $\mathbf{4}$ has the following properties: ${ }^{1} \mathrm{H}$ $\operatorname{NMR}\left(\mathrm{CDCl}_{3}, 500 \mathrm{MHz}\right) \delta: 6.85(\mathrm{dd}, J=15.7,8.0 \mathrm{~Hz}, 1 \mathrm{H}), 5.79(\mathrm{~d}, J=15.7 \mathrm{~Hz}, 1 \mathrm{H}), 4.84(\mathrm{t}, J=4.6 \mathrm{~Hz}, 1 \mathrm{H}), 4.18(\mathrm{q}, J=7.1 \mathrm{~Hz}$, 2H), 3.92-4.00 (m, 2H), 3.81-3.89 (m, 2H), 2.34 (septet, $J=7.0 \mathrm{~Hz}, 1 \mathrm{H}), 1.61-1.68(\mathrm{~m}, 2 \mathrm{H}), 1.48-1.54(\mathrm{~m}, 2 \mathrm{H}), 1.29(\mathrm{dt}, J=7.1,0.5$ $\mathrm{Hz}, 3 \mathrm{H}), 1.07(\mathrm{~d}, J=6.7 \mathrm{~Hz}, 3 \mathrm{H}) ;{ }^{13} \mathrm{C} \mathrm{NMR}\left(\mathrm{CDCl}_{3}, 100 \mathrm{MHz}\right) \delta: 167.0,154.0,120.3,104.5,65.09,65.08,60.4,36.6,31.7,30.2$, 19.6, 14.5; IR (film) 2958, 2926, 1718, 1653, 1458, 1368, 1267, 1178, 1144, 1037, $987 \mathrm{~cm}^{-1}$; GCMS calcd for $\mathrm{C}_{12} \mathrm{H}_{20} \mathrm{O}_{4}$ (M) 228 , found $228 .[\alpha]^{22} \mathrm{D}=+23\left(\mathrm{c}=1.7, \mathrm{CHCl}_{3}\right)$. The ee was determined by HPLC analysis with an Agilent 1100 Series HPLC system equipped with a CHIRALPAK IA column (length $250 \mathrm{~mm}$, I.D. $4.6 \mathrm{~mm}$; hexanes/isopropanol 99:1,1.0 mL/min) with $\mathrm{t}_{\mathrm{r}}($ minor) $=9.6$ min, $\mathrm{t}_{\mathrm{r}}($ major $)=10.3 \mathrm{~min}$. The purity $(>95 \%)$ was determined by GC analysis $\left(\mathrm{t}_{\mathrm{r}}=4.48 \mathrm{~min}\right)$, using the same conditions as for compound 1 .
} 


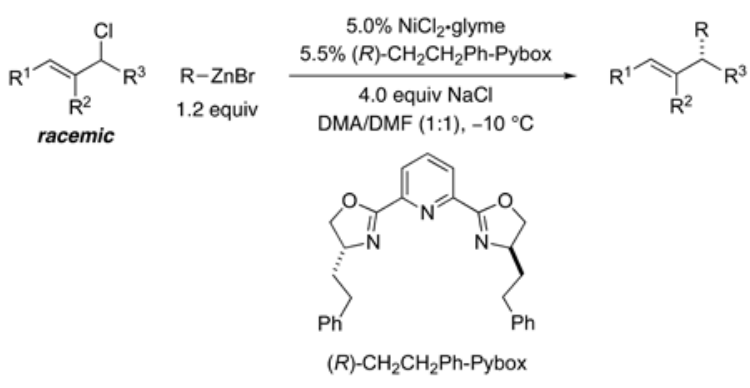

In the case of "symmetrical" allylic halides (e.g., entries 1-4 of Table 1), regioselectivity in the carbon-carbon bond formation is not an issue. As the steric demand of the substituents on the termini of the allyl fragment increases, the ee decreases (entries 1-3). A bulky 1,2,3trisubstituted allylic chloride undergoes cross-coupling with excellent enantioselectivity, although modest yield (entry 4). An unactivated alkyl chloride is compatible with the reaction conditions (entry 2 ).

In the case of unsymmetrical allylic chlorides, if the two substituents on the termini of the allyl group have similar steric and electronic properties, then the regioselectivity is modest (e.g., 1.9:1 for $n$-Bu vs. Me; entry 5 of Table 1). On the other hand, good regioselectivity and enantioselectivity are observed when there is substantial steric (entries 6 and 7; >20:1 regioselectivity) or electronic (entries 8-10; >20:1 regioselectivity) differentiation. Carboncarbon bond formation occurs preferentially at the less-hindered site (entries 5-7) or at the site that preserves conjugation (entries 8 and 9).

Ethyl (E)-4-chloropent-2-enoate (2) and 2-[2-(1,3-dioxolan-2-yl)ethyl]zinc bromide (3) were selected as the cross-coupling partners because the product serves as an intermediate in our formal total synthesis of fluvirucinine $A_{1}$ (Scheme 1).7,10 The Negishi reaction proceeded with a strong preference for carbon-carbon bond formation at the $\gamma$ position of the electrophile, providing compound 4 in excellent yield (94-96\%), regioselectivity (>20:1), and ee (94-95\%). Reduction of $\mathbf{4}$, followed by bromination, furnished $\mathbf{5}$, which was converted into the organozinc reagent and subjected to a second asymmetric Negishi crosscoupling with a racemic allylic chloride to afford intermediate $\mathbf{6}$ in good yield (82\%), regioselectivity (>20:1), and stereoselectivity (>98\% ee; $15: 1 \mathrm{dr})$. This coupling product can be transformed into aldehyde 7, which was an intermediate in Suh's total synthesis of fluvirucinine $\mathrm{A}_{1} \cdot 10$

\section{References}

2. Rodríguez S, Kneeteman M, Izquierdo J, López I, González FV, Peris G. Tetrahedron. 2006; 62:11112-11123.

3. For a review of halide effects in transition-metal catalysis, see: Fagnou K, Lautens M. Angew Chem, Int Ed. 2002; 41:26-47.

4. Lou S, Fu GC. Organic Syntheses. submitted.

5. For reviews, see: (a) Pfaltz, A.; Lautens, M. Comprehensive Asymmetric Catalysis. Jacobsen, EN.; Pfaltz, A.; Yamamoto, H., editors. Vol. 2 Chapter 24. Springer; New York: 1999. (b) Trost BM, Van Vranken DL. Chem Rev. 1996; 96:395-422. [PubMed: 11848758] See also: Kar A, Argade NP. Synthesis. 2005:2995-3022.

6. For additional examples and for reviews, see: (a) Consiglio G, Morandini F, Piccolo O. J Chem Soc, Chem Commun. 1983:112-114. (b) Gomez-Bengoa E, Heron NM, Didiuk MT, Luchaco CA, Hoveyda AH. J Am Chem Soc. 1998; 120:7649-7650. (c) Chung K-G, Miyake Y, Uemura S. J 
Chem Soc, Perkin Trans. 2000; 1:15-18. (d) Chen H, Deng MZ. J Organomet Chem. 2000; 603:189-193. (e) Yorimitsu H, Oshima K. Angew Chem, Int Ed. 2005; 44:4435-4439. (f) Alexakis A, Malan C, Lea L, Tissot-Croset K, Polet D, Falciola C. Chimia. 2006; 60:124-130. (g) Novak A, Fryatt R, Woodward S. Comptes Rendus Chimie. 2007; 10:206-212.

7. Son S, Fu GC. J Am Chem Soc. 2008; 130:2756-2757. [PubMed: 18257579]

8. For a convenient method for the preparation of alkylzinc halides from alkyl halides, see: Huo S. Org Lett. 2003; 5:423-425. [PubMed: 12583734]

9. For leading references on cross-couplings of alkyl electrophiles, see: (a) Rudolph A, Lautens M. Angew Chem Int Ed. 2009; 48:2656-2670. (b) Frisch AC, Beller M. Angew Chem Int Ed. 2005; 44:674-688.(c) Netherton, MR.; Fu, GC. Topics in Organometallic Chemistry: Palladium in Organic Synthesis. Tsuji, J., editor. Springer; New York: 2005. p. 85-108. (d) Netherton MR, Fu GC. Adv Synth Catal. 2004; 346:1525-1532.

10. For the total synthesis of fluvirucinine $A_{1}$, see: Suh YG, Kim SA, Jung JK, Shin DY, Min KH, Koo BA, Kim HS. Angew Chem, Int Ed. 1999; 38:3545-3547.

\section{Appendix. Chemical Abstracts Nomenclature; (Registry Number)}

Ethyl (E)-4-oxo-2-butenoate: 2-Butenoic acid, 4-oxo-, ethyl ester, (2E)-; (2960-66-9)

Methylmagnesium bromide: Magnesium, bromomethyl-; (75-16-1)

Ethyl (E)-4-hydroxy-2-pentenoate: 2-Pentenoic acid, 4-hydroxy-, ethyl ester, $(2 E)$-; (10150-92-2)

Dichlorotriphenylphosphorane: Phosphorane, dichlorotriphenyl-; (2526-64-9)

Imidazole: 1H-Imidazole; (288-32-4)

Ethyl (E)-4-chloropent-2-enoate: 2-Pentenoic acid, 4-chloro-, ethyl ester, (2E)-; (872455-00-0)

2-(1,3-Dioxolan-2-yl)ethyl bromide: 1,3-Dioxolane, 2-(2-bromoethyl)-; (18742-02-4)

Zinc; (7440-66-6)

2-[2-(1,3-Dioxolan-2-yl)ethyl]zinc bromide: Zinc, bromo[2-(1,3-dioxolan-2-yl)ethyl]-; (864501-59-7)

Nickel(II) chloride, dimethoxyethane adduct ( $\mathrm{NiCl}_{2} \cdot$ glyme): Nickel, dichloro[1,2di(methoxy-кO)ethane]-; (29046-78-4)

2,6-Bis[(S)-4,5-dihydro-4-(2-phenylethyl)-2-oxazolyl]pyridine: Pyridine, 2,6-bis[(4S)-4,5dihydro-4-(2-phenylethyl)-2-oxazolyl]-; (1012042-02-2)

Sodium chloride; (7647-14-5)

(S,E)-Ethyl 6-(1,3-dioxolan-2-yl)-4-methylhex-2-enoate: 2-Hexenoic acid, 6-(1,3dioxolan-2-yl)-4-methyl-, ethyl ester, (2E,4S)-; (1012041-93-8) 


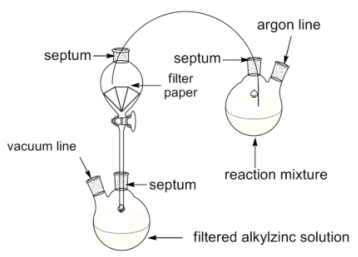

Figure 1. 


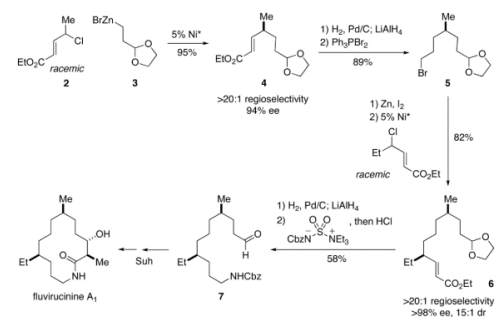

Scheme 1.

Formal Total Synthesis of Fluvirucinine $A_{1}$ via Two Catalytic Enantioselective Negishi Cross-Couplings of Allylic Chlorides $\left((R)-\mathrm{CH}_{2} \mathrm{CH}_{2} \mathrm{Ph}\right.$-Pybox was used; for the reaction conditions, see Eq 1). 


\section{Table 1}

Enantioselective, Stereoconvergent Negishi Cross-Couplings of Allylic Chlorides (for the reaction conditions, see Eq 1).

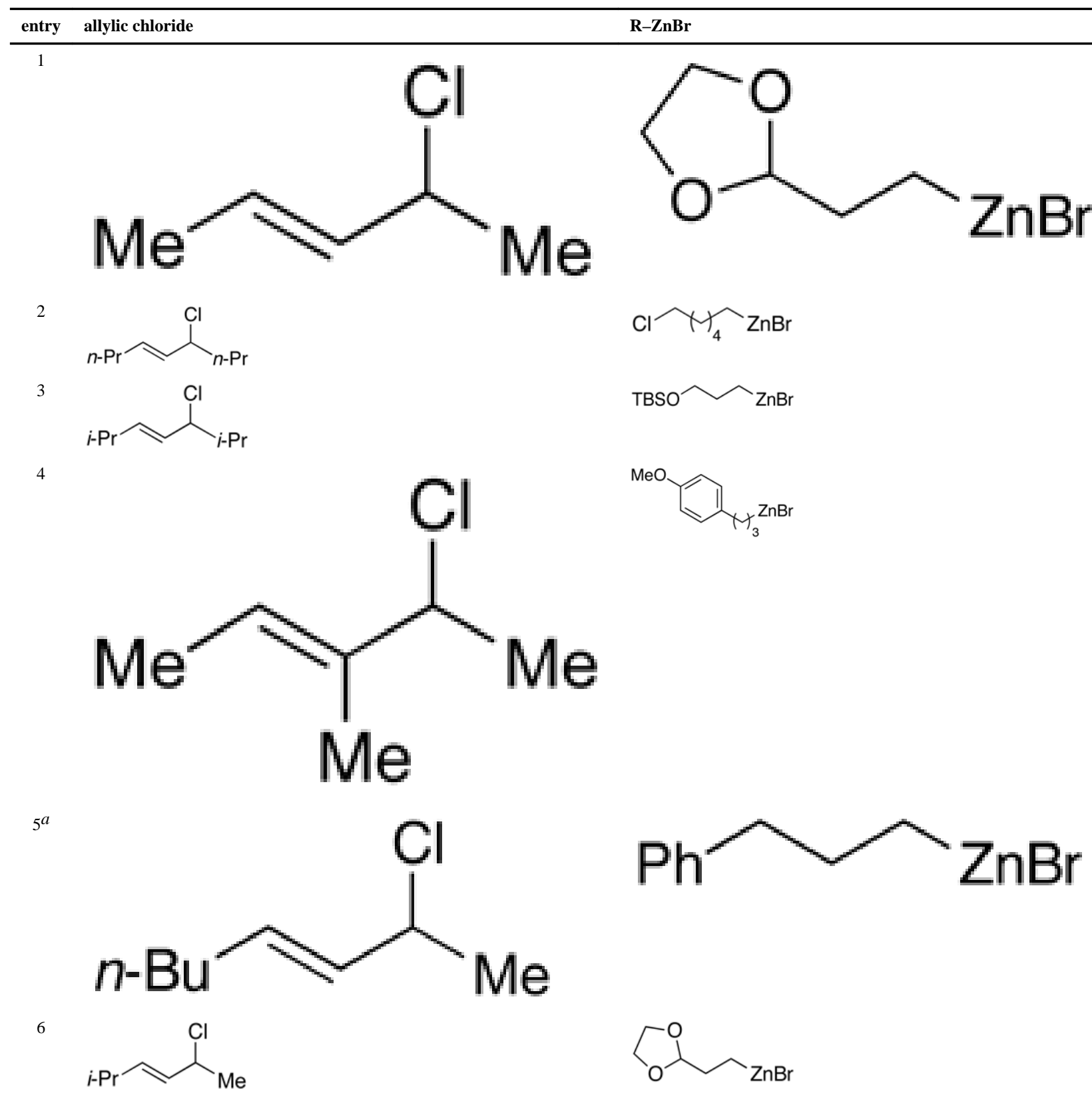




\begin{tabular}{|c|c|c|c|}
\hline entry & allylic chloride & $\mathrm{R}-\mathrm{ZnBr}$ & ee $(\%)$ \\
\hline 7 & & & 81 \\
\hline
\end{tabular}<smiles>CC(N)/C=C/Br</smiles>

8

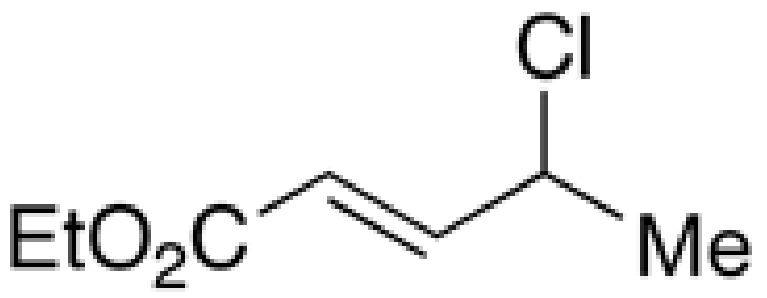

9<smiles>COC=CC(C)Cl</smiles>

10

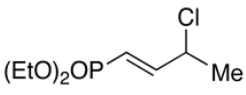

$\mathrm{Me}$<smiles>CC(C)=CCCC1CC1</smiles>
$\mathrm{Me}$

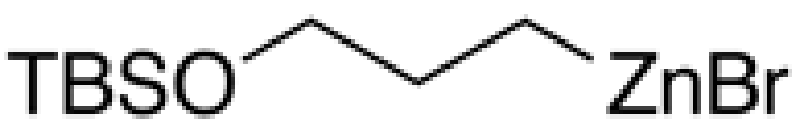

$n$-Hex- $\mathrm{ZnBr}$
93

90

${ }^{a}$ Regioselectivity: 1.9:1; ee of the minor regioisomer: $88 \%$. 